kommen, so hätte ich in der Hauptsache das zu leisten gehabt, was Lesne uns bringt, nämlich den Nachweis, daß mit dem 9. Jahrhundert das Bistum mit der Kathedrale, das Kloster mit der Klosterkirche als Haupt und mit allem Bistums- bzw. Klostergut als Zubehör in Gestalt des episcopatus oder episcopium und der abbatia Sache zu werden anfängt, so daß 50 Jahre später der Begriff des Benefiziums und wieder einige Jahrzehnte nachher die Benefizialleihe darauf Anwendung finden kann und schließlich die französischen und anderen Mediatbistümer ganz, die Reichsbistümer so gut wie völlig Eigenkirchen, jene der Großen, diese des Königs werden. Die Beobachtung Lesnes, daß der episcopatus und das episcopium bzw. die abbatia anfänglich das ganze Bistums- bzw. Klostergut, nicht bloß die spätere mensa episcopalis bzw. abbatialis umfaßt haben, ist in dieser Beziehung sehr wertvoll und macht den Parallelismus mit der voraufgegangenen Entwicklung des niederen kirchlichen Benefiziums vollkommen, wenn man nur nach dem von mir oben S. 504 gegen den Verfasser Ausgeführten sich darüber klar ist, daß auch die einfache parrochia, ecclesia, capella und das beneficium an ihr ursprünglich alles Einzelkirchengut mit einschloB, und daß das spätere Benefizialvermögen, um mich so auszudrücken, nur Pfarrtafelgut ist.

So ist zwar der von Lesne unternommene Versuch, die Entstehung des kirchlichen Benefizialwesens zu schildern, mißglückt, seine Arbeit aber ein willkommener Beitrag zur Geschichte des höheren Eigenkirchenwesens und für die Richtigkeit der Eigenkirchen- und der damit zusammenhängenden Benefizialtheorie eine um so glänzendere Bestätigung, als sie eigentlich gegen sie gerichtet sein sollte und infolgedessen höchst unfreiwillig für sie Zeugnis ablegt.

Clrich Stutz.

\title{
E. Lesne, La dîme des biens ecclésiastiques aux IXe et $\mathrm{Xe}$ siècles. Louvain 1913. $82 \mathrm{~S}$.
}

Das vorliegende Buch, eine Fortsetzung der gelehrten Studien seines Verfassers über das Kirchengut in fränkischer Zeit, vereinigt vier in der Revue d'histoire ecclésiastique XIII und XIV (Louvain $1912 \mathrm{f}$.) erschienene Abhandlungen; es kündigt zugleich ein demnächst zu veröffentlichendes Werk über das Kirchengut in karolingischer Zeit an (S. 73; Revue XIV, S. 501).

Es ist an dieser Stelle unmöglich, den Inhalt des Buches in wenig Worte zusammenzupressen; es muß genügen hervorzuheben, daß es reiche, ausgebreitete Gelehrsamkeit mit angenehmer Schreibart verbindet. Immerhin sollen einige Ergebnisse angemerkt werden. Die kirchlichen Güter waren nicht vom kirchlichen Zehnten befreit; der Zehnte der villae war an die Pfarrkirche, später an das Stift oder an die Abtei zu entrichten. Vom dominicum wurde der Zehnte für das hospitale pauperum, später für die mensa fratrum erhoben: les moines ou chanoines, d'abord exempts de dîmes, firent ensuite consister leur exemption à 
être seuls en leurs domaines à les recueillir (S. 81; Revue XIV, S. 509). Adalhard, Abt von Corbie ( $\uparrow 826)$, hat die Anlage und die Erhebung dieser Zehnten in ebenso ausführlichen wie bemerkenswerten Verordnungen geregelt; er verstand es, sinnreiche Mittel anzuwenden, durch die er, ebenso menschenfreundlich wie sparsam, die Mühen und Kosten der Herbeischaffung und der Gewinnung zehntpflichtiger Früchte zu verringern wußte. (S. 30-44; Revue XIII, S. 662-674). Besonders wichtig ist die Darstellung des Eigentums an diesen Zehnten und ihrer Bestimmung, ohne daß ich überall mit dem Verfasser übereinzustimmen vermöchte. Wenn er meint, sein besonderes Thema sei bisher unbekannt gewesen und noch nicht behandelt, so darf ich entgegnen, daB ich in meiner Histoire de la dime ecclésiastique jusqu'au décret de Gratien (1909), S. 123f. auf die Zehnten für Armen- und Krankenhäuser sowie für Fremdenherbergen von mehreren Bischöfen und Stiftern aufmerksam gemacht habe; E. Lesne hat diese immerhin knappen Andeutungen meiner Erstlingsarbeit zu ergänzen und zu erweitern verstanden. Sind aber, wie er behauptet (S. 66; Revue XIV, S. 494), diese Zehnten von kirchlichen Gütern wirkliche Zehnten? Ich für mein Teil verneine die Frage, da der Gläubiger und der Schuldner eine und dieselbe Person sind, zwischen beiden also keine Obligation, von keinem eine Steuer an den andern möglich ist. Da solche Lage hier zutrifft, bilden jene Zehnten un chapitre spécial au budget monastique (S. 68), die Einkünfte des Armenamtes bei der Abtei, und es kommt wenig darauf an, daß der Verfasser das hospitale an die Stelle der Pfarrkirche als Empfänger treten läßt (S. 63-66; Revue XIV, S. 491-494).

Lille.

P. Viard.

E. Seckel, Benedictus Levita decurtatus et excerptus. Eine Studie zu den Handschriften der falschen Kapitularien: Sonderabdruck aus der Festschrift der Berliner Juristenfakultät für Heinrich Brunner (München und Leipzig, Duncker und Humblot 1914), S. 377-464.

E. Seckels Forschungen über Benedictus Levita, über Pseudoisidor sowie die Synode von Rouen stellen bereits in sich selbst eine kleine Bibliothek dar, so daß es vielleicht nicht unerwünscht ist, wenn wir ihre Einzelbestandteile durch eine bibliographische Aufnahme zu veranschaulichen versuchen. ${ }^{1}$ ) $\mathrm{Da} ß$ sie ständiger Vermehrung zugänglich

1) E. Seckel, Studien zu Benedictus Levita I-VIII, 1: Neues Archiv der Gesellschaft für ältere deutsche Geschichtskunde XXVI (1901), S. 37-72. XXIX (1904), S. 275-331. XXXI (1906), S. 59-139. XXXIV (1909), S. 319-381. XXXV (1910), S. 105-191. 433-539. XXXIX (1914), S. 327-431; Pseudoisidor: Realenzyklopädie für protestantische Theologie und Kirche XVI (3. Aufl. Leipzig 1905), S. 265-307; Die ältesten Canones von Rouen: Historische Aufsätze K. Zeumer dargebracht (Weimar 1911), S. $611-636$. 